ENERGY SOURCES, PART A: RECOVERY, UTILIZATION, AND ENVIRONMENTAL EFFECTS 2017, VOL. 39, NO. 12, 1298-1306

\title{
An Estimation of a trace gaseous emission factor from combustion of common fuelwood species in South-western Nigeria
}

\author{
B. S. Fakinle ${ }^{a}$, O. B. Okedere ${ }^{\text {b }}$, O. Seriki ${ }^{c}$, A. J. Adesanmi ${ }^{d}$, and J. A. Sonibare ${ }^{d}$ \\ ${ }^{a}$ Department of Chemical Engineering, Landmark University, Omu-Aran, Kwara State, Nigeria; bFaculty of \\ Engineering, Osun State University, ' ${ }^{\mathrm{O} O s o g b o}$, Nigeria; ${ }^{\mathrm{C}}$ Global Environmental Technology Limited, Lagos, \\ Nigeria; \\ ${ }^{d}$ Environmental Engineering Research Laboratory, Department of Chemical Engineering, Obafemi Awolowo \\ University, Ile-Ife, Nigeria
}

\section{ABSTRACT}

The current electricity shortage from Nigeria's national grid and the scarcity of refined petroleum products including kerosene which is used for domestic purposes make the use of fuelwoods more dominant in the country; especially in the rural areas. Air emissions from open burning of predetermined quantity of some common fuelwoods identified in regions were characterized for gaseous air pollutants using the E8500 combustion analyzer. The measured concentrations were used to calculate emission factors of the air pollutants. The emission factors for the gaseous emission from the fuelwoods were 181.84-6547.57 g/kg for CO, 44.07-2986.40 g/kg for HC, 2.24$267.36 \mathrm{~g} / \mathrm{kg}$ for NOx while SO2 had $0.0-9.87 \mathrm{~g} / \mathrm{kg}$. This study establishes that Gliricidia sepium had the minimum emission factor for all the considered gaseous pollutants except for SO2, thus all stakeholders considering the adoption of fuelwood in the country's quest for increased energy mix can be properly guided on the pollutants associated with the investigated fuelwoods. This may help in the choice of appropriate air pollution control.

KEYWORDS

Air pollution; emission factor; energy mix; fuelwood 